\title{
Thermal environment and sudden infant death syndrome: case-control study
}

\author{
Anne-Louise Ponsonby, Terence Dwyer, Laura E Gibbons, Jennifer A Cochrane, Michael E Jones, \\ Michael J McCall
}

\begin{abstract}
Objective-To compare the thermal environment of infants who died of the sudden infant death syndrome with that of age matched control infants.

Design-Case-control study. Infants who died were matched with two controls, one for age and one for age and birth weight. Thermal measurements were conducted at the death scene for cases and at the scene of last sleep for control infants, who were visited unexpectedly within four weeks of the index infant's death on a day of similar climatic conditions. A follow up questionnaire was administered to parents of cases and controls.
\end{abstract}

Setting-The geographical area served by the professional Tasmanian state ambulance service, which includes $94 \%$ of the Tasmanian population.

Subjects -41 infants died of the sudden infant death syndrome at home; thermal observations at death scene were available for $28(68 \%)$, parental questionnaire data were available for $40(96 \%) .38$ controls matched for age and $\mathbf{4 1}$ matched for age and birth weight.

Results - Cases had more excess thermal insulation for their given room temperature $(2.3$ togs $)$ than matched controls $(0.6$ togs $)(p=0.009)$. For every excess thermal insulation unit (tog) the relative risk of the sudden infant death syndrome was 1.26 ( $95 \%$ confidence interval 1.05 to 1.52 ). The average thermal bedding value calculated from parental recall was similar to that observed by attendant ambulance officers (mean difference $=0.4$ tog, $p=0.39$ ). Cases were more likely to have been found prone (odds ratio $4.58 ; 1.48$ to 14.11 ). Prone sleeping position was not a confounder or effect modifier of the relation between excess thermal insulation and the syndrome.

Conclusions-Overheating and the prone sleeping position are independently associated with an increased risk of the sudden infant death syndrome. Further work on infant thermal balance and sudden infant death is required and guidelines for appropriate infant thermal care need to be developed.

\section{Introduction}

Descriptive epidemiological studies of the sudden infant death syndrome have shown a winter excess of cases in most countries.' Analytical studies have provided further evidence of an inverse association between the syndrome and climatic temperature. ${ }^{23}$ Falls in climatic temperature have been related to an increased incidence of the sudden infant death syndrome about six days later in England and Australia.$^{45}$ A north to south geographical gradient of increasing incidence of the syndrome exists in both Australia and New Zealand and the regional incidence within these countries is inversely related to mean annual temperature. ${ }^{6}$
Mechanisms proposed to explain the association between the sudden infant death syndrome and low temperature include hypothermia, increased viral illness, and indirect hyperthermia, the last being due to altered child care practices in response to cold weather. Recent work has shown that some infants do experience thermal stress and has also provided evidence that infant hyperthermia may play a part in the aetiology of the sudden infant death syndrome.

In New Zealand some infants have been found to be inappropriately dressed for their thermal environment, and the insulation of such infants was correlated with external but not room temperature. ${ }^{7}$ In the United Kingdom a study on the overnight environment of infants found that parents increased thermal insulation by $188 \%$ for only a $4.4{ }^{\circ} \mathrm{C}$ drop in room temperature. ${ }^{8}$ Case series have provided evidence of overheating in some sudden infant deaths ${ }^{910}$ and postmortem changes consistent with heatstroke for some infants." Bass investigated four cases of simultaneous cot death in twins and found an overheated environment was a common factor. ${ }^{12}$ In New York a study based on investigation of the scene where death occurred, conducted within a week of death, found evidence of overlying, asphyxia, or hyperthermia in some of the cases studied. ${ }^{13}$ Nelson et al have proposed a theoretical model of thermal balance which implicates hyperthermia and the prone sleeping position in the sudden infant death syndrome ${ }^{14}$ They propose that particular cultural combinations of infant care practices (sleeping position, clothing, bedding, and room heating) may facilitate hyperthermia and explain widely disparate rates of the syndrome in different countries and ethnic groups. In the United Kingdom, Fleming et al found that babies dying of the syndrome were more likely to be prone, be heavily wrapped, and to have had heating on all night when compared with population based controls. ${ }^{15}$ They concluded that overheating and the prone position were independently associated with an increased risk of sudden infant death. This study has important public health implications, but the findings have been criticised as information was collected by interview with bereaved parents and hence subject to recall bias. ${ }^{1617}$

It has been recommended that the role of thermal balance in sudden infant death should be assessed with investigation of the death scene by a trained observer. ${ }^{714}$ We report the observed thermal environment at the death scene of babies who died of the sudden infant death syndrome and control infants matched for age and birth weight. We examined room temperature and thermal insulation.

\section{Subjects and methods}

The source population consisted of all infants residing in the geographical area served directly by the 
professional state ambulance service. Professional ambulance officers cover $94 \%$ of the Tasmanian population directly. Case infants were those who died suddenly at home from birth to 1 year of age and who were later classified as having died of the sudden infant death syndrome after postmortem examination. For each case two control infants were selected from the same hospital as the index case ( 35 cases) or from the nearest participating hospital in the same region as the index case (six cases) by using hospital maternity records. Control A was matched for age (so that the control infant would be the same age at interview as the index case was at death) and control B was matched for age and birth weight $(<1500 \mathrm{~g}, 1500-2499 \mathrm{~g}, \geqslant 2500 \mathrm{~g})$.

We investigated the thermal environment at the scene of death for cases and scene of last sleep for control infants. Meteorological information for the day was obtained from regional weather stations. For cases the thermal environment was measured by the ambulance officers attending the scene of an infant's death. Ambient room temperature was measured with a Brennan alcohol based thermometer placed near the head of the infant's bed. The quantity and type of clothing and bedding were observed and recorded. Home heating, ventilation, window condensation, and sleeping arrangements were also observed. External air temperature was recorded by a Brennan alcohol based thermometer within $200 \mathrm{~m}$ of the home. Information on the position in which the deceased infant was found was requested from the parents. Additional information was obtained, including the degree of facial obstruction of the infant at discovery and some findings from external examination of the infant, such as body temperature. The ambulance officers were trained in death scene investigation using the same clinical instruction process that applies to other emergency settings. In addition, a written set of instructions was placed in each ambulance which officers followed if called to a sudden unexpected infant death.

A comprehensive verbal questionnaire was administered to the bereaved parents six weeks after their baby's death. This included details on housing, heating and ventilation patterns, infant feeding, exposure to tobacco smoke, usual sleeping position, movement during sleep, sweating during sleep, parental age, education and employment, infant illness, immunisation, medical and child health clinic care, and postnatal growth.

Control infants were usually visited within four weeks of the death of the index baby (74\% (40/54) visited within two weeks, 98\% (53/54) visited within four weeks). The visit was conducted on a day with a similar minimum temperature to the day on which the index baby died. Control interviews were not prearranged and parents were invited to participate at the door step. This was done to avoid the measurement bias that could have occurred if the parents were expecting the visit and therefore changed the conditions of the infant's room to give a more favourable impression. Visits were conducted at a similar time of day to that at which the index death was discovered. The thermal environment was measured in the room where the infant was sleeping or had slept. The questionnaire was administered directly after measuring the thermal environment or as soon as possible thereafter.

All infants dying suddenly and unexpectedly in Tasmania during the study received a postmortem examination by a hospital pathologist. Toxicological and bacteriological studies were routinely performed.

\section{ASSESSMENT OF THERMAL RESISTANCE}

The total thermal resistance for each infant's clothing and bedding was calculated in a similar fashion to that used in a previous study of the sudden infant death syndrome and infant clothing and bedding. ${ }^{15}$ Calculations were based on published values for the thermal resistance of each material. ${ }^{18}$ The values were expressed in togs (the tog value of a fabric is defined as 10 times the temperature difference in ${ }^{\circ} \mathrm{C}$ between its two faces when the heat flow is equal to $\left.1 \mathrm{w} / \mathrm{m}^{2}\right)$. For example, the thermal resistance of an unbrushed blanket is $1.5 \mathrm{tog}$. An estimate of the proportion of surface area covered by each item and these tog values were then used to calculate an effective total thermal resistance for the coverings of each infant. ${ }^{15}$ The tog value for bedding items which were swaddled around the infant was multiplied by two to adjust for the increased thermal resistance introduced by swaddling. Blankets and other bedding were estimated to cover $80 \%$ of the infant's surface area. This means that the effective thermal resistance of an unbrushed blanket was calculated to be $1 \cdot 2$ tog.

Typical values of the thermal resistance of Australian adult quilts and some infant bedding items were obtained from the division of wool technology of the Commonwealth Scientific and Industrial Research Organisation (G R S Naylor, personal communication). The thermal resistance of various types of infant quilts was measured and a weighted average tog value for polyester cot quilts was determined by combining these results with the distribution of infant polyester quilt types found in the concurrent Tasmanian cohort study. These values were used in the calculation of the infant's total thermal resistance. A thermal balance model has been devised by the Shirley Institute, Manchester (E Clulow, personal communication), to provide the thermal insulation required for thermal equilibrium of the healthy sleeping infant at various room temperatures, allowing for the body surface area covered by various items and assuming heat is uniformly lost over the whole body. The model is based on the formula of Burton and Edholm ${ }^{19}$ and gives a theoretical tog value for a range of temperatures. For example, in a room at $8{ }^{\circ} \mathrm{C}$, the amount of thermal insulation required would be $7 \cdot 2$ tog; at $20^{\circ} \mathrm{C}, 3 \cdot 8$ tog; and at $28{ }^{\circ} \mathrm{C}, 1.5$ tog. These tog values have been adjusted to allow for the body surface area covered by various items. We used this model to define the extent to which a given infant is inappropriately dressed for a given room temperature.

\section{STATISTICAL METHODS}

The model for thermal balance was used to assess the relation between room temperature and the total thermal insulation (tog) value for the clothing and bedding over the infant. The difference between the observed tog value and the tog value recommended for the room temperature by the model was assessed as a risk factor and will be referred to as excess thermal insulation. The odds ratio and $95 \%$ confidence interval were calculated by conditional logistic regression ${ }^{20}$ with epidemiological graphics, estimation and testing (EGRET) 0.25.1 software, or a variation of the MantelHaenszel test ${ }^{21}$ with Epi Info5.01 software from the Centers for Disease Control, United States. These methods preserve the matching of cases and controls in the analysis, allowing each case to be compared directly with its controls. For continuous variables analysis of variance was used to assess differences between cases and controls. This method also preserved the matching between cases and controls and is analogous to a paired $t$ test. An unpaired $t$ test was used to compare mean values within the case or control group. These procedures were conducted with SAS 6.03 software. Variables thought to be associated with excess thermal insulation values or the sudden infant death syndrome were considered as possible confounders and interactions between extra togs and other factors were examined. One set of controls was additionally 
matched for birth weight because previous work had suggested that the thermal environment of an infant might be influenced by birth weight. We found no evidence of an association between excess thermal insulation and birth weight and the two groups were pooled. The effect of birth weight on the association between excess thermal insulation and the sudden infant death syndrome was also examined.

\section{Results}

From 1 October 1988 to 5 September 1990, 41 infants died suddenly at home and were later found to have died of the sudden infant death syndrome. In six of these cases the ambulance did not attend the home: in three the infant was taken directly to hospital, in two the family doctor was called, and in one the infant was taken to a friend's house. In 35 cases, an ambulance was called to the home and in $28(80 \%)$ the entire thermal environment protocol was conducted. This report is based on these 28 cases. Reasons for noncompletion of the protocol included active resuscitation with transport to hospital and parental request. The follow up questionnaire was conducted in 40 of the 41 cases. The initial response rate for all controls $(n=79)$ was $84 \%$. The main reason for non-response was inability of the interviewer to contact the initial control family at home within the specified time constraints. If the initial control was a non-respondent a new control infant was selected. Of the 28 case infants, 26 had both controls. Two index infants were matched with only one infant (for age and birth weight). Table I shows the age distribution of cases. The age of the 54 control infants was within 7 days of age for 23 and of the 28 index cases and within 14 days for all cases.

The minimum temperature on the day of death of the cases was within $1{ }^{\circ} \mathrm{C}$ of the minimum day temperature at assessment for $31 \%$ (17) of controls and within $3{ }^{\circ} \mathrm{C}$ for $67 \%$ (36) of controls. There were no significant differences in minimum temperature, maximum temperature, humidity, wind speed, dew point, visibility, or cloud cover between the case and control groups on the day of measurement. Of the 28 case infants six died in autumn, 11 in winter, six in spring, and five in summer.

For cases, the time between discovery of the deceased infant and measurement of room temperature was small; in over half the cases room temperature was measured within 30 minutes of discovery of the infant (table II). We found no evidence of a trend of decreasing room temperature with increasing delay in measurement. Parents were asked at follow up interview if they had opened the external door of the house or altered the window, door, or heating of the infant's room before the ambulance attended. For the 14 cases whose families had done one or more of the above, the mean room temperature $\left(18 \cdot 1^{\circ} \mathrm{C}\right)$ was not significantly different from that $\left(18.2^{\circ} \mathrm{C}\right)$ for cases whose parents had not altered the infant's environment $(p=0 \cdot 93)$. For controls, the room temperature was slightly lower for the nine infants who were asleep during interview $\left(15.8{ }^{\circ} \mathrm{C}\right)$ than for the 45 who were awake $\left(16.8^{\circ} \mathrm{C}\right)$, although this difference was not significant $(p=0 \cdot 56)$. The thermal environment was measured at night (12.01 am-6.00 am) for one case and no controls; in the morning (6.01 am-12 noon) for 19 cases and 37 controls; in the afternoon (12.01 pm-6.00 pm) for one case and five controls; and in the evening (6.01 pm-12 midnight) for seven cases and 12 controls.

\section{RISK FACTORS}

Table III shows matched univariate odds ratios with $95 \%$ confidence intervals for variables concerning the thermal environment. For cases all data except for those on illness were collected by ambulance staff. Signs and symptoms of illness in the days preceding the death were recorded at follow up interview. The variable illness is composite and refers to the presence of snuffles, cough, noise in chest, fever, and episodes of vomiting or diarrhoea, or both, in the day preceding or the day of interview or death.

TABLE III-Risk factors for sudden infant death associated with thermal environment

\begin{tabular}{|c|c|c|}
\hline Risk factors & $\begin{array}{l}\text { Univariate } \\
\text { odds ratio }{ }^{\star}\end{array}$ & $\begin{array}{l}95 \% \text { Confidence } \\
\text { interval }\end{array}$ \\
\hline \multicolumn{3}{|l|}{ Continuous: } \\
\hline $5^{\circ} \mathrm{C}$ Increase in room air temperature & 1.57 & 0.85 to 2.91 \\
\hline 1 Tog increase in thermal insulation & $1 \cdot 17$ & 0.99 to 1.38 \\
\hline $5{ }^{\circ} \mathrm{C}$ Increase in external air temperature & $1 \cdot 10$ & 0.49 to 2.49 \\
\hline $\begin{array}{l}\text { Dichotomous (reference group in brackets): } \\
\text { Thermal insulation }=6-10 \text { togs }\end{array}$ & & \\
\hline $\begin{array}{l}\text { (Thermal insulation }<6 \text { togs) } \\
\text { Thermal insulation }=\geqslant 10 \text { togs }\end{array}$ & $1 \cdot 36$ & 0.48 to 3.85 \\
\hline $\begin{array}{l}\text { (Thermal insulation }<6 \text { togs) } \\
\text { Found prone after last sleep }\end{array}$ & $3 \cdot 78$ & 0.63 to $22 \cdot 65$ \\
\hline (Not found prone after last sleep) & $4 \cdot 58$ & $1 \cdot 48$ to $14 \cdot 11$ \\
\hline $\begin{array}{l}\text { Home heating on during part or all of interval } \dagger \\
\text { (No home heating on during time interval } \dagger \text { ) } \\
\text { Infant swaddled during last sleep }\end{array}$ & ${ }_{10 \cdot 50}$ & 1.30 to 85.05 \\
\hline $\begin{array}{l}\text { (Infant not swaddled during last sleep) } \\
\text { Ventilation grate in room }\end{array}$ & $2 \cdot 90$ & $0 \cdot 87$ to $9 \cdot 68$ \\
\hline $\begin{array}{l}\text { (No ventilation grate in room) } \\
\text { Open door in room during last sleep }\end{array}$ & $0 \cdot 45$ & 0.15 to 1.38 \\
\hline $\begin{array}{l}\text { (Closed door in room during last sleep) } \\
\text { Window condensation in room }\end{array}$ & $0 \cdot 39$ & 0.12 to 1.23 \\
\hline $\begin{array}{l}\text { (No window condensation in room) } \\
\text { History of recent illness }\end{array}$ & $0 \cdot 36$ & 0.07 to 1.90 \\
\hline $\begin{array}{l}\text { History of recent illness } \\
\text { (No history of recent illness) }\end{array}$ & $2 \cdot 33$ & 0.78 to 6.98 \\
\hline
\end{tabular}

$\star$ Based on conditional logistic regression.

tHome heating on during interval since infant last seen alive and to time found dead or comparable period for control infants.

The average room temperature for cases $\left(18 \cdot 1{ }^{\circ} \mathrm{C}\right)$ was higher than that for controls $\left(16.6^{\circ} \mathrm{C}\right)$ but this was not significant $(\mathrm{p}=0 \cdot 15)$. The external air temperature was similar (case mean $=12.6{ }^{\circ} \mathrm{C}$, control mean= $\left.12 \cdot 1{ }^{\circ} \mathrm{C}, \mathrm{p}=0 \cdot 83\right)$. Average thermal insulation over the infants was higher in cases $(6.6$ tog) than controls $(5 \cdot 3$ tog; $p=0 \cdot 05)$.

Cases were significantly more likely to have been found in the prone position (odds ratio 4.58). In addition, cases were more likely to have had heating on in the house during the time last seen alive to time found dead compared with the same period for controls (odds ratio $10 \cdot 50$ ). The matched odds ratio is high because although 17 of the cases were concordant with regard to home heating when compared with their matched control group, in all but one of the discordant sets the case had heating on but at least one of the matched controls did not.

Table IV shows matched univariate odds ratios with $95 \%$ confidence intervals for variables measured by verbal questionnaire. Information for one case was not complete. Cases were more likely to have been born to young mothers or mothers who smoked, to have been bottle fed, and to have usually slept in the prone

TABLE IV - Maternal and infant factors affecting risk of sudden infant death

\begin{tabular}{lcc}
\hline Risk factors (reference group in brackets) & $\begin{array}{c}\text { Univariate } \\
\text { odds ratio }^{\star}\end{array}$ & $\begin{array}{c}95 \% \text { Confidence } \\
\text { interval }\end{array}$ \\
\hline $\begin{array}{l}\text { 5ear increase in maternal age } \\
\text { Male infant }\end{array}$ & 0.42 & 0.22 to 0.78 \\
$\begin{array}{l}\text { (Female infant) } \\
\text { Maternal postnatal smoking } \\
\text { No maternal postnatal smoking) }\end{array}$ & $1.00 \dagger$ & 0.39 to $2.56 \dagger$ \\
$\begin{array}{l}\text { Some breast milk } \\
\text { (Formula milk only) }\end{array}$ & 5.69 & 1.87 to 17.29 \\
$\begin{array}{l}\text { History of sweating during sleep } \\
\text { No history of sweating during sleep) }\end{array}$ & 0.38 & 0.14 to 1.02 \\
$\begin{array}{l}\text { Usual sleeping position prone } \\
\text { (Usual sleeping position not prone) }\end{array}$ & 1.95 & 0.80 to 4.71 \\
$\begin{array}{l}\text { Maternal education }>10 t h \text { grade } \\
\text { Maternal education } \leqslant 10 \text { th grade) }\end{array}$ & 5.97 & 1.69 to 21.11 \\
$\begin{array}{l}\text { Birth order in family }>1 \\
\text { (Birth order 1) }\end{array}$ & 0.53 & 0.20 to 1.44 \\
\hline
\end{tabular}

^Based on conditional logistic regression.

†Based on a variance estimator for the Mantel-Haenszel odds ratio. 
TABLE V-Difference in thermal insulation reported for infants by parents and by ambulance officers

\begin{tabular}{lc}
\hline $\begin{array}{l}\text { Difference in thermal } \\
\text { insulation (togs) }\end{array}$ & $\begin{array}{c}\text { No of } \\
\text { infants } \\
(\mathrm{n}=27)\end{array}$ \\
\hline-4.9 to -4 & 1 \\
-3.9 to -3 & 2 \\
-2.9 to -2 & 3 \\
-1.9 to -1 & 4 \\
-0.9 to -0.1 & 5 \\
0 & 5 \\
0.1 to 0.9 & 2 \\
1.0 to 1.9 & 1 \\
2.0 to 2.9 & \\
3.0 to 3.9 & 4 \\
4.0 to 4.9 & \\
\hline
\end{tabular}

TABLE VI - Excess thermal insulation in case and control infants

\begin{tabular}{ccr}
\hline & \multicolumn{2}{c}{ No of infants } \\
\cline { 2 - 3 } $\begin{array}{l}\text { Excess thermal } \\
\text { insulation (togs) }\end{array}$ & $\begin{array}{c}\text { Cases } \\
(\mathrm{n}=28)\end{array}$ & $\begin{array}{c}\text { Controls } \\
(\mathrm{n}=54)\end{array}$ \\
\hline$<-4$ & 1 & \\
-4 to $-2 \cdot 1$ & 2 & 5 \\
-2 to $-0 \cdot 1$ & 4 & 21 \\
0 to 1.9 & 7 & 13 \\
2 to 3.9 & 5 & 11 \\
4 to 5.9 & 4 & 3 \\
6 to 7.9 & 4 & 1 \\
$\geqslant 8$ & 1 & \\
\hline
\end{tabular}

position. The average birth weights were $3020 \mathrm{~g}$ (95\% confidence interval 2775 to $3264 \mathrm{~g}$ ) for cases, $3451 \mathrm{~g}$ (3278 to $3624 \mathrm{~g}$ ) for controls matched for age, and $3070 \mathrm{~g} \mathrm{(2787}$ to $3353 \mathrm{~g}$ ) for controls matched for age and birth weight. Sixty three per cent (17/27) of cases had a history of occasional or frequent sweating during sleep compared with $44 \%$ (23/52) of matched controls; $30 \%(8 / 27)$ of cases and $8 \%(4 / 52)$ of matched controls had a history of sweating to the degree that beads of sweat were visible on the infant's brow or the infant's clothes became wet. Swaddling during last sleep was inversely associated $(p=0.01)$ with room temperature.

Body temperature was measured in 22 of the 28 cases. Four of the 19 infants who had rectal temperature measured were found to have a core temperature of $37{ }^{\circ} \mathrm{C}$ or greater and eight had temperatures of $33-35^{\circ} \mathrm{C}$. Three infants who had only armpit temperature recorded had temperatures of $33{ }^{\circ} \mathrm{C}, 35^{\circ} \mathrm{C}$, and $36^{\circ} \mathrm{C}$. The average period between the time the infant was last seen alive and the time of the recording was seven hours.

In $25 \%$ (7/28) of cases ambulance officers noted signs of perspiration (on the infant or bed clothes). Eleven (39\%) were reported to the ambulance officers to be found face down in the prone position and two were reported to have been entirely under the bedding.

Information on bedding was recorded by ambulance staff and at interview for 27 of the 28 cases (table V). The average tog value of bedding reported by parents five weeks after the death was slightly higher than that reported by ambulance staff (mean difference $=$ 0.4 tog), but this difference was not significant $(p=0 \cdot 39) .{ }^{6}$ For the five cases whose bedding reports differed by more than 4 togs the ambulance report (parental report) was as follows: case one, two quilts (one quilt); case two, one layer of quilt (large quilt doubled over); case three, bedspread (quilt); cases four the five, no quilt (quilt on top of other bedding).

\section{THERMAL ENVIRONMENT MODEL}

Thermal insulation over each infant was plotted against room temperature (figure). To assess formally the thermal environment of each infant, the difference between the infant's observed tog value and the theoretical tog value recommended for the observed room temperature (as denoted by the black line) was assessed as a risk factor. The units of this risk factor were therefore defined in togs and called excess thermal insulation, with the result that infants who were underdressed for a given room temperature had a negative value. Table VI shows the excess thermal

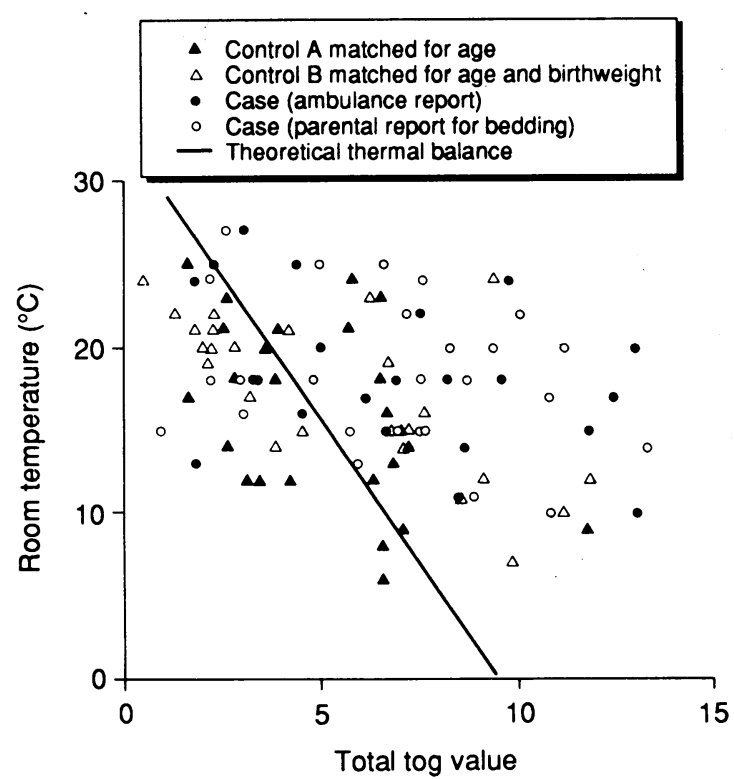

insulation distribution of cases and controls. The mean value for excess thermal insulation was $2 \cdot 3$ (SD 3.4) togs for cases and 0.6 (SD 2.3) togs for controls. Thus cases were more likely to be overdressed for room temperature than control infants $(p=0 \cdot 009)$.

Conditional multiple logistic regression was used to compare the excess thermal insulation in cases and controls. For every excess thermal insulation unit the relative risk of the sudden infant death syndrome was $1.26(95 \%$ confidence interval 1.05 to 1.52$)$ with the ambulance staff report of bedding. For example, infants with two extra togs of thermal insulation than the model recommended were 1.6 times more likely to be cases than controls and infants with four excess togs were 2.5 times more likely to be cases. This risk estimate did not change if the additional loading for swaddling was removed from the method of calculation of the thermal insulation, confirming that the association was not due to more cases being swaddled during last sleep than controls. Substitution of the bedding value reported by parents for that observed by ambulance staff gave a similar estimate of risk: for every excess thermal insulation unit (tog) the relative risk was $1.38(1.09$ to 1.73$)$.

\section{THERMAL ENVIRONMENT AND ILLNESS}

Excess thermal insulation was positively associated with illness in cases and controls. The average excess thermal insulation was higher in the 21 case infants with illness (mean $2.7 \mathrm{tog}$ ) than in the six without illness $(0 \cdot 28$ tog; $p=0 \cdot 13)$. The average excess thermal insulation was also higher in the 32 controls with illness $(0.93 \mathrm{tog})$ than in the 22 without illness $(0.03)$ tog; $p=0 \cdot 17)$. Both cases and controls with illness were more likely than healthy infants to have been excessively dressed for their given room temperature, though due to the small numbers in each group the differences were not significant.

We then examined whether the finding of a positive association between the sudden infant death syndrome and excess thermal insulation reflected the fact that case infants were more likely to have had illness and infants with illness were more likely to have been overdressed. This was done by treating illness as a confounder in the multivariate model. After adjusting for effect of illness on the association between excess thermal insulation and the sudden infant death syndrome for every excess thermal insulation unit the risk of the syndrome increased 1.20 times $(0.99$ to $1 \cdot 46)$. If the bedding value obtained by parental recall was used the risk increased by $1.35(1.07$ to 1.70$)$ for every unit of excess thermal insulation. Thus excess thermal insulation is a risk factor independent of the presence of illness.

Prone sleeping position, maternal smoking, maternal age, external air temperature, time of day, home heating, infant feeding, and infant birth weight were also found not to be confounders or effect modifiers of the relation between excess thermal insulation and the sudden infant death syndrome. Infant sex was not a confounder of this association but a significant interaction term $(p=0.03)$ was present in the model, suggesting that the effect of excess thermal insulation was stronger in females than males.

\section{CASES WITH INCOMPLETE DATA}

Thirteen cases of the sudden infant death syndrome occurred within the source population for which there was no death scene investigation. Information on the death scene of these infants was obtained by questionnaire six weeks after the death. Twelve of these cases were matched to two controls and one was matched to only one control (for age and birth weight).

The average total insulation in these cases was $7 \cdot 3$ (SD 3.0) togs. The average total insulation in the 
controls was $5 \cdot 7$ (SD 3.4) togs. Nine cases $(69 \%)$ had home heating on during the time between last being seen alive and being found dead compared with 15 $(63 \%)$ of controls. Nine cases $(69 \%)$ usually slept prone compared with eight $(32 \%)$ controls. Thus, there was a similar tendency for these cases to be overdressed, more likely to have home heating on, and more likely to have usually slept prone compared with control infants.

\section{Discussion}

We found infants who had died of the sudden infant death syndrome to be significantly overdressed for a given room temperature compared with control infants. These findings add to the accumulating evidence that hyperthermia is important in sudden unexpected infant death. Our study is based on direct observation of the thermal environment at the death scene and therefore avoids the problem of bias from parental recall bias. In addition the control infants were visited unexpectedly to avoid measurement bias and external climatic conditions were held constant within the study design.

Disadvantages of this study are that for cases the measured room temperature is not the actual room temperature at death and that the ambulance officers described only the observed clothing and bedding and hence altered items may have been omitted. Although two of the 28 infants were found completely under the bedding, this was not taken into account in the surface area calculations as similar information was not available for controls. The use of a weighted average value for the polyester cot quilts of cases and controls makes estimation of thermal insulation less accurate. These disadvantages would, however, be more likely to bias the results towards the null hypothesis and hence the finding of a significant association between the sudden infant death syndrome and a warm environment is important.

Mean tog values for case bedding were similar whether ambulance or parental reports were used. In a few cases, however, the reports disagreed. In some cases it seems that bedding was removed or altered before the ambulance officers recorded observations and in others recall bias may have contributed to the discrepancy. Recall bias would be more likely to be a problem in our follow up parental interview, conducted at six weeks, than in the study of Fleming $e t a l$, in which the parental questionnaire was administered within 72 hours of the death. ${ }^{\text {is }}$

\section{OTHER FACTORS AFFECTING THERMAL STATE}

Room temperature and the clothing and bedding are only two of several factors which will contribute to the thermal state of an infant. Nelson et al have produced a theoretical model of heat balance which takes into account some of these additional factors. ${ }^{14}$ The prone sleeping position will reduce heat loss by reducing the body surface area available for heat loss. In the heavily dressed infant, the head has an important thermoregulatory role which will be compromised by placing the head down or underneath bedding. Respiratory heat loss, which accounts for around $7 \%$ of total $\operatorname{loss}^{22}$ will be reduced by facial obstruction. A high ambient vapour pressure will reduce evaporative heat loss. Infection increases the infant's basic metabolic rate and increases heat generation.

In our study not only were case infants more likely to be overclothed for room temperature than control infants but they were significantly more likely to be prone and they were also more likely to have a history of recent illness, although this difference was not significant. In addition, more than a third of cases had some evidence of facial obstruction at death and some infants were found completely under bedding. Given these additional factors and the finding that cases were in a significantly higher thermal environment than controls, it could be inferred that the infants who died were in a relative state of hyperthermia compared with controls. Consistent with this, the recorded body temperatures for cases were not low, even though the readings were taken, on average, seven hours after the infants were last seen alive.

We chose the thermal environment model of Clulow ${ }^{1 \times}$ rather than the more complex model of Nelson et al. Firstly, information was not collected on all the factors required to calculate actual infant heat balance. Secondly, the separate effects of prone sleeping position and illness on the association between excess thermal insulation and the sudden infant death syndrome would be more difficult to assess with a more derived model. We found no evidence to support the hypothesis that prone sleeping position alters the association between excess thermal insulation and the syndrome. However, the sample size may have been too small to detect an interaction between these two factors.

The thermal environment of both cases and controls was found to be higher in those infants with evidence of illness than those without. Parents may respond to infections in their babies by increasing the amount of clothing and bedding ${ }^{23}$ or warming the infant..$^{2+}$ This is clearly concerning and has implications for health education. The finding that the positive association between excess thermal insulation remained after adjustment for illness status excludes the possibility that the association was due only to illness.

\section{FURTHER WORK}

Tasmania has a temperate climate and only a small proportion of homes have central heating $(1 \%$ of infants in the concurrent cohort study live in centrally heated homes). ${ }^{25}$ Even so, the proportion of infants who were underdressed for room temperature in this study was low. We are therefore unable to comment on the relation between hypothermia and the sudden infant death syndrome but will continue to collect information on the thermal environment of infants dying of the syndrome. Additional information is also required to examine whether our finding that the strength of association between excess thermal insulation and the sudden infant death syndrome varies by sex also exists in a large study sample after adjustment for other factors.

Although the pathogenesis of the sudden infant death syndrome remains unclear, it may be considered as a biphasic event with the first set of factors operating to predispose the infant and the second set of factors acting as loading factors which operate at a critical stage of the infant's development. A warm environment could lead to sudden infant death by direct hyperthermia, ${ }^{14}$ thermolabile syncope with cerebral ischaemia, ${ }^{26}$ impaired respiratory control, ${ }^{15}$ enhancement of the laryngeal closure reflex, ${ }^{27}$ altered sleep state,,$^{28}$ or depressed arousal. ${ }^{29}$ An asphyxial mode of death would also be more likely, particularly in heavily dressed infants found prone and face down.

In conclusion, we found infants who died of the sudden infant death syndrome to be significantly more likely to be overdressed for the room temperature at the death scene and in the prone position compared with control infants. These findings support a previous recommendation that "educating parents about sleeping position and correct thermal care of their babies may help reduce the incidence of sudden infant deaths." 15 Further work on the thermal balance of infants at the time of sudden death is required, and parental guidelines on appropriate thermal care of infants should be developed. 
We thank the Tasmanian Government and the Sudden Infant Death Research Foundation (South Australia) for their support; Dr G Naylor, division of wool technology, Commonwealth Scientific and Industrial Research Organisation, and $\mathrm{Mr} \mathrm{R}$ Dreaper, Sheridan Domestic Textiles for information about the thermal insulation of clothing and bedding items; the Tasmanian Sudden Infant Death Syndrome Society for help with computing equipment; Ego Pharmaceuticals for providing their products; Sr D McCracken, Sr H Bain, Mrs S Cameron, and the officers of the Tasmanian Ambulance Service for data collection; the departments of hospital pathology, police, and justice for their cooperation; and the families who participated in this study. Dr A L Ponsonby holds a National Health and Medical Research Council public health training and development scholarship.

1 Golding J, Limerick S, Macfarlane A. Sudden infant death: patterns, puzzles, and problems. Shepton Mallet: Open Books Publishing, 1985.

2 Bonser BSA, Knight BH, West RR. Sudden infant death syndrome in Cardiff. Association with epidemic influenza and with temperature. Int $f$ Epidemiol 1978;7:335-40.

3 Greenberg MA, Nelson KE, Carnow BW. A study of the relationship between sudden infant death syndrome and environmental factors. Am $\mathcal{F}$ Epidemiol 1973;98:412-23

4 Murphy MFG, Campbell MJ. Sudden infant death syndrome and environmental temperature: an analysis using vital statistics. $\mathcal{F}$ Epidemiol Community Health 1987;41:63-71.

5 Campbell MJ. Sudden infant death syndrome and environmental temperature: further evidence for a time-lagged relationship. Med $\mathcal{F}$ Aust 1989;151:365-7.

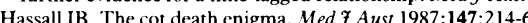

7 Tuohy PG, Tuohy RJ. The overnight thermal environment of infants. Nohy PG, Tuohy RJ. The
NZ Med I 1990;103:36-8.

8 Wailoo MP, Petersen SA, Whittaker H, Goodenough P. The thermal environment in which 3-4 month old infants sleep at home. Arch Dis Child environment in wh

9 Bacon C, Scott D, Jones P. Heatstroke in well wrapped infants. Lancet $1979 ;$ ii: $42-5$
10 Stanton AN. Overheating and cot death. Lancet 1984;ii:1199-201.

11 Stanton AN, Scott DJ, Downham MAPS. Is overheating a factor in some unexpected infant deaths? Lancet $1980 ; 0: 1054-7$.

2 Bass M. Sudden infant death syndrome. N Engl f Med 1982;307:891-2.

13 Bass M, Kravath RE, Glass L. Death-scene investigation in sudden infant death. N Engl f Med 1986;315:100-5.

14 Nelson EAS, Taylor BJ, Weatherall IL. Sleeping position and infant bedding may predispose to hyperthermia and the sudden infant death syndrome. Lancet 1989;i:199-201.

15 Fleming PJ, Gilbert R, Azaz Y, Berry J, Rudd P, Stewart A, et al. Interaction between bedding and sleeping position in the sudden infant death syndrome: a population based case-control study. BMF 1990;301:85-9.

16 Southall D, Stebbens V, Samuels M. Bedding and sleeping position in the sudden infant death syndrome. $B M J$ 1990;301:492.

17 Guntheroth WG, Spiers PS. Bedding and sleeping position in the sudden infant death syndrome. $B M \mathcal{F} 1990 ; 301: 494$.

18 Clulow E. Thermal insulating properties of fabrics. Textiles 1978;1:2.

19 Burton AC, Edholm OG. Man in a cold environment. London: Edward Arnold, 1955

20 Breslow NE, Day NE. Statistical methods in cancer research. Vol 1. The analysis of case-control studies. Lyons: International Agency for Research on Cancer, 1980.

21 Robins J, Greenland S, Breslow NE. A general estimation for the variance of the Mantel-Haenszel odds ratio. Am F Epidemiol 1986;124:719-23.

22 Hey EN, Katz G. Evaporative water loss in the new-born baby. 7 Physiol 1969;200:605-19.

23 Nelson EAS, Taylor BJ. Infant clothing, bedding and room heating in an area of high postneonatal mortality. Paediatr Perinat Epidemiol 1989;3:146-56.

24 Eiser C, Town C, Tripp J. Dress and care of infants in health and illness. Arch Dis Childhood 1985;60:465-70.

25 Australian Bureau of Statistics. Nutional energy survey, household appliances, facilities and insulation, Australia. 1985-86. Canberra: Australian Bureau of Statistics, 1987. (Cat No 8212.0.)

26 Sunderland R, Emery JL. febrile convulsions and cot death. Lancet 1981 ;ii: 176-8.

27 Haraguchi S, Fung RQ, Sasaki CT. Effect of hyperthermia on the laryngeal closure reflex: implications in the sudden infant death syndrome. Ann Otol Rhinol Laryngol 1983;92:24-8.

28 Parmeggiani PL. Interaction between sleep and thermoregulation: an aspect of the control of behavioural states. Sleep 1987;10:526-35.

29 Scott $S$. Bedding and sleeping position in the sudden infant death syndrome. BMF 1990;301:493.

(Accepted 25 November 1991)

\title{
Can the fall in Avon's sudden infant death rate be explained by changes in sleeping position?
}

\author{
Ruth E Wigfield, Peter J Fleming, P Jem Berry, Peter T Rudd, Jean Golding
}

Institute of Child Health, Bristol BS2 8BJ Ruth E Wigfield, MRCP, research fellow Peter J Fleming, FRCP, consultant paediatrician Jean Golding, PHD, professor of paediatric and perinatal epidemiology

\section{St Michael's Hospital, Bristol BS2 8EG \\ P Jem Berry, MRCPATH, professor of paediatric pathology}

Bath Unit for Research into Paediatrics, Bath BA1 3NG Peter T Rudd, MD, consultant paediatrician

Correspondence to:

Dr P J Fleming,

Department of Child

Health, St Michael's

Hospital, Bristol BS2 8EG.

$B M f$ 1992;304:282-3

\section{Abstract}

Objective-To examine the impact of changing practice with regard to infant sleeping position on mortality from the sudden infant death syndrome.

Design-A population based study of all infants dying suddenly and unexpectedly during February 1990 to July 1991, and two groups of controls; one comprising every 125th baby born to Avon residents and the other comprising pairs of infants matched to each index case for age, neighbourhood, and date of study. Information about sleeping position was collected at home visits soon after the index baby's death or, for the population based controls, on several occasions in the first six months of life. The design was comparable to that of an earlier study of the same population.

Setting-County of Avon.

Subjects -35 infants who died suddenly and unexpectedly ( 32 of the sudden infant death syndrome), 70 matched controls, and 152 population based controls.

Results - The prevalence of prone sleeping in the matched controls was much lower than that found in an earlier study in Avon (28\% (18/64) 1990-1 v 58\% (76/131) 1987-9; $p<0.001$ ) and was comparable with the prevalence in population based controls $(29 \%)$. This would be expected to lead to a reduction in the incidence of the sudden infant death syndrome to $2 \cdot 0 / 1000$ live births $(95 \%$ confidence interval $1 \cdot 8 / 1000$ to $2 \cdot 5 / 1000$ ). The actual mortality fell from $3 \cdot 5 / 1000$ in $1987-9$ to $1 \cdot 7 / 1000$.

Conclusion-The fall in mortality can be almost entirely accounted for by the reduction in prone sleeping, suggesting a causal relation exists between them. Side and supine positions confer protection but the side position is unstable and the infant may roll prone. We therefore recommend supine as the safest sleeping position for babies.

\section{Introduction}

The prone sleeping position has been associated with a higher risk of sudden infant death than the side or supine position in every published controlled study that has considered it. The calculated relative risks vary between 1.9 and $12.5 .^{1}$ If this association were causal a change in practice with regard to sleeping position within a defined population should lead to a parallel change in the sudden infant death rate. Preliminary results from the Netherlands and Australia suggest this may be so..$^{23}$

During November 1987 to April 1989, while the prone position was still being actively encouraged, a population based, case-control study in Avon found a relative risk of 8.8 for the prone position. ${ }^{4}$ These results aroused considerable interest and debate and prompted many local health care professionals to alter their advice to parents. As part of the continuing study of sudden infant deaths in Avon we examined the impact of changing positioning practice on mortality. To enable valid comparison with the previous Avon study the same basic design was used, but we also recruited an unmatched, population based control group. This was to determine how far conclusions based on the highly selected matched control group could be extrapolated to the whole community. 